Journal of Tourism and Hospitality Management

December 2017, Vol. 5, No. 2, pp. 1-14

ISSN: 2372-5125 (Print), 2372-5133 (Online)

Copyright (C) The Author(s). All Rights Reserved.

Published by American Research Institute for Policy Development

DOI: $10.15640 /$ jthm.v5n2a1

URL: https://doi.org/10.15640/jthm.v5n2a1

\title{
Analysis of Tourism in the Republic of Macedonia 1945-2015
}

\author{
Nikola V. Dimitrov ${ }^{1}$
}

\begin{abstract}
The paper analyzes the tourism in the Republic of Macedonia for the period 1945-2015. Tourism is explored through a case study of Butler's Talc model of life cycle of tourism, in the Republic of Macedonia - a small Balkan continental tourist destination. The analysis is based on primary and secondary data sources for a period of 70 years. The paper points out and recommends practical advice fop motivating key players in forming economic policy for tourism development.
\end{abstract}

Keywords: Liife cycle, talc model, tourist destiantion, Macedonia

\section{Introduction}

Tourism as a global process is present in all countries including the Republic of Macedonia. Every country designs, adopts and implements strategies aimed at attracting more tourists and raising the competitive position in the global tourism (Agarwal, 2002; Avraham \& Ketter, 2015; Huybers, 2007; Pike, 2005). The paper deals with the life cycle of tourism in the Republic of Macedonia from 1945 to 2015 according to the model of Butler (Butler, 1980). Because of its continental geostrategic location, R. Macedonia functions as a bridge for the southern Balkan states, or more broadly speaking between Southeast Europe and Southwest Asia. (Figure 1) Historically and traditionally it is considered a space rich in various natural, cultural, social and economic values.

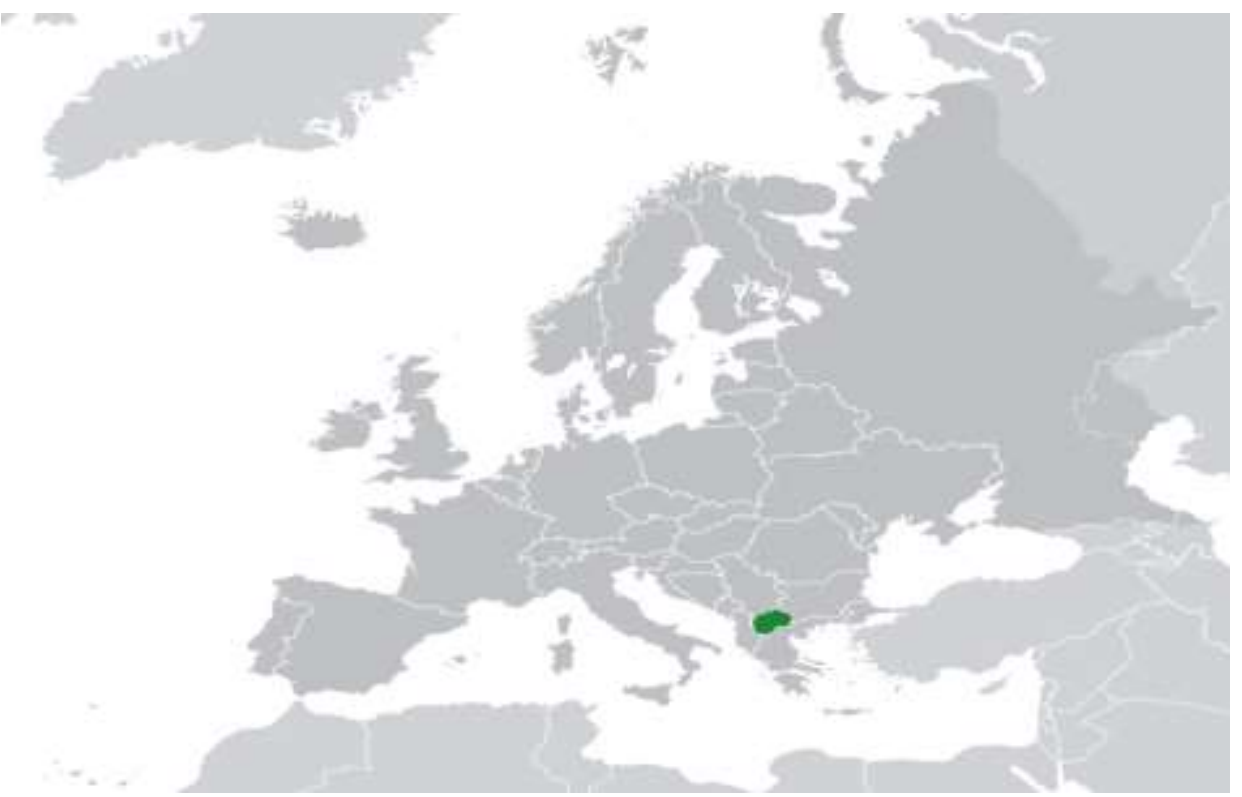

Figure 1. Geographical location of the Republic of Macedonia in Europe

${ }^{1} \mathrm{PhD}$, Associate Professor, Tourism geography, Faculty of tourism and business logistics, University Goce Delcev, Stip, R.Macedonia, nikola.dimitrov@ugd.edu.mk 
In recent years much of the Macedonian economy has been geared towards the service sector and in this context, tourism has become one of the main "industries" in the state. The dynamics of the Macedonian tourism over the last few years, despite the changing situations of its main markets, is constantly increasing, particularly the number of tourist overnight stays. The focus is on the role of social communities through the various stages in the development of tourism running from the '50s onwards, and especially in the ' $60 \mathrm{~s}$, '70s and '80s when tourism gained massive character.

The study with objective, to identify the stages of development or life cycle (talc) model of tourism, for eighty years or between 1945 and 2015, and to explore the role of social communities and govermment in the process of policy making and planning related to the development of tourism of mass production and consumption.

\section{Methodology}

According to Butler (Butler, 2009) the talc model works well for destinations whose lifespan was founded a century ago or more. One of the main values of the talc is that it interprets several evolutionary stages of tourism development. The talc model interprets the changes in the number of tourists visiting the area (demand) and the subsequent expansion of infrastructure, mainly that of accommodation (offer) and communication (transport).

Special attention is paid to public intervention in the development and characterization of tourism, local stakeholders and the relationship between the two. Butler, as a custom set of theories has previously been used in many fields, such as sociology and management. The model is quite recognizable when it explains the development of tourism in certain areas or countries (see Figure 2).

At the same time the Butler model is represented through several stages and theories of scenarios. The process begins with phase "survey" of the tourist area where a small group of tourists are attracted to the natural and cultural environment and are interested to visit and stay in the studied tourist area. In the second phase, called "inclusive" local initiatives produce activities for the development of tourist facilities and enhancement of the area by increasing the number of new tourists.

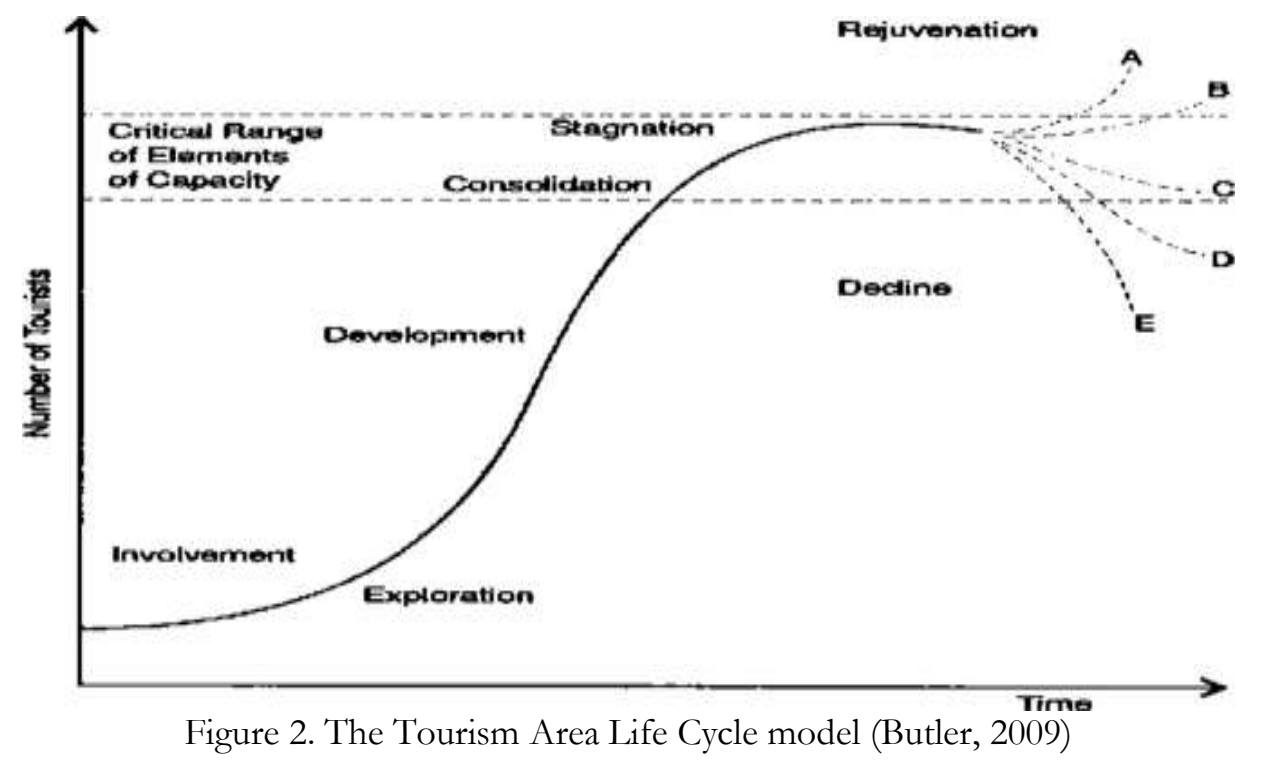

The third phase, "development", is characterized by a progressive increase in the number of tourists, who are attracted by the increased promotion of the destination. In the next phase, "consolidation" the rate of visits by tourists can decrease, despite the fact that in absolute terms this is not perceived. The next stage, "stagnation" is known for record numbers of tourists, but the destiantion is no longer a fashionable one, it becomes conservative, part of the tourism infrastructure is now used by other types of businesses etc. 
From this point, many scenarios are possible. Initially, if there is no reorientation of tourism through the activities of private local stakeholders or the public administration, destinations will enter the sixth stage called "decline" in which the hospitality area is not able to compete with its rivals and is found in a spacious and numerical recession. However, if private local stakeholders and the public administration conduct some reorientation of the tourist area, its tourist activities may enter a different phase. This phase involves reorientation or re-discovery of the tourist area, and consequently the sixth phase will fit rejuvenation dedicated almost completely to changing the features and attractions of the tourist area. Following the publication of the article for talc model (Butler, 1980), there were and still are frequent bibliographic references to the model in addressing various aspects in the development of different tourist spots but also opening up new topics for discussion. Among them are those who debated on the functionality of the model, especially the transition between Fordist and post-Fordist phase (Lagiewski, 2009).

\section{Results and discussion}

The entire tourist period from 1945 to 2015 is a typical example of the TALC model with all stages of the life cycle of the destination. Namely, after the end of the Second World War, from 1945 to 1991, Macedonia was federal units of the SFR Yugoslavia. The first years after the war is a period of reconstruction and industrialization, with insufficiently developed material base for the development of tourism.

The period from 1947 to 1953, named as the investigation phase is characterized by a centralized administrative system of planning and management of the economy, with a focus on domestic tourism. The new phase of involvement of tourism starts from 1954-1968, when the country introduced incentives for the development of tourism, through the abolition of the beneficial treatment of the workers resorts and starting free pricing, introducing grants for hospitality facilities, construction of accommodation facilities, etc. In 1957-1961 the material basis in hospitality significantly increased (Baseski, 1976; Karanfilovski, 1967).

The number of tourists was increasing primarily due to various measures and activities undertaken for the introduction of "open doors" ("opendoor") and the policy of "good neighbor" of the government. The years between 1961-1965 influenced by economic and currency reforms had seen a significant expansion in the international tourism. In the period from 1965-1990, the tourism industry is categorized as an activity of special importance in the overall economic development.

Around the same time, in most countries in Western Europe, this Fordist phase of mass tourism (from 1959 onwards) was represented by a new system of accumulation and coherent model for the regulation of activities in tourism based on mass production and consumerism as well as consolidation of welfare. This phase of the new social and economic paradigm is known as the Golden Age of capitalism, where tourism played a leading role in most Western countries and is considered the fourth wave that changed the lives of most of its citizens (Dower, 1965).

In Macedonia, the character of tourism is beginning to change, namely a new influx of tourists. These new tourists were not traditional - domestic, but foreign tourists from neighboring countries, as well as tourists from other European countries (the first Germans, French, British, Dutch tpirists etc. came), attracted by the Macedonian sun, natural beauty and cultural affinities, and of course the low prices of the underdeveloped destinations (Ohrid, Prespa, Dojran, Skopje, etc.). With the growth in the number of visitors and overnight stays, the number of accommodation facilities of small low-quality hotels moderately increased, the financing for which was done by the local capital.

During the development phase (1969-1980) the government engaged in meaningful interventions including the introduction of tax credits, construction of new tourist facilities, use of loans and credits for Regional Development and a number of other stimulating elements designed to boost tourism demand. In the observed period high investments were noted in tourism, and tourism is characterized as an activity of particular importance for the overall economic development. This also applies to a new stage in the assumption of the talc model which means involvement of the country's political economy in one of the most important steps in using funds from the World Bank for Macedonia. Therefore, from the early seventies the construction of large and modern hotels began in all major cities in the country, which is one of the most important steps in the development of tourism.

In the mid-seventies in Macedonia, the number of hotels was 51, motels 16, labor resorts 24, auto camps 5, baths 6 , mountaineering homes and houses 6 , and tourism agencies were located in the major cities and tourist centers (Dimitrov \& Koteski, 2015; Panov, 1996; Stojmilov \& Tosevska, 2016). On the one hand, from the natural and cultural perspective, Macedonia is seen as an exotic destination with a long history, untouched and unknown to tourists. 
On the other hand, the increase in supply and demand, results in increased revenue, the active involvement of the local economy and some technological improvements and especially attractive charters have become favorable for the development of the tourism in the region. His work focuses heavily on promotion of Macedonian tourism (from a national point of view only, excluding regional peculiarities) and was less concerned with regulation and intervention. In fact, the goal was not to interfere too much with activity while enjoying spectacular growth and driving the rest of the economy. However, the total lack of regulation (especially in terms of territorial planning of local destinations) was supposed to have a crucial impact in the future.

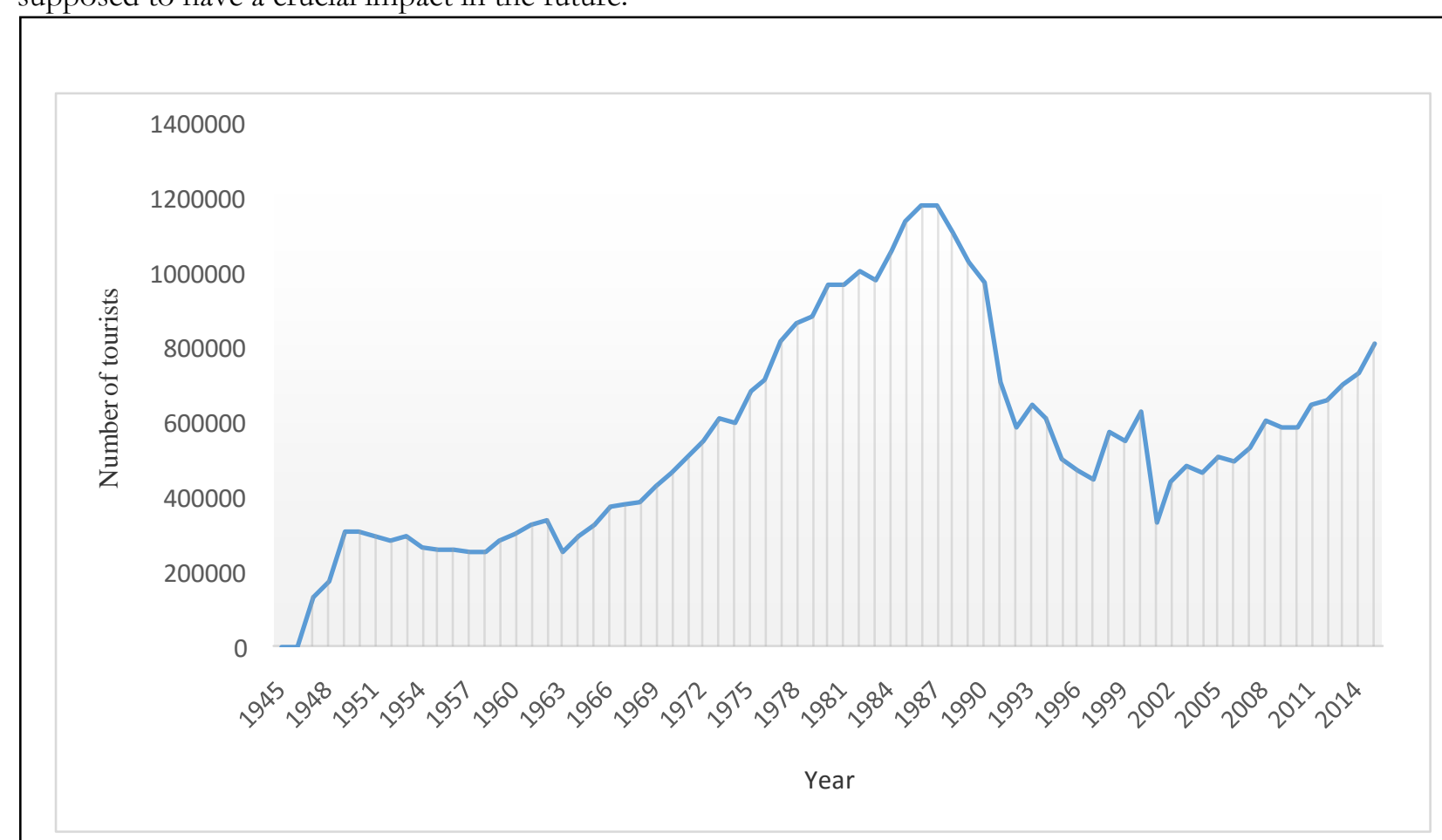

Source: SSO, 1956-1988; SSO, 1991-2016; SSO, 2003-2009; 2006-2015

Figure 3. The movement of tourists in R. Macedonia for the period 1945-2015

At the end of the 70s, the demand continued to grow, compensated by strong growth in national demand, resulting from growth in the Macedonian gross domestic product per capita. Finally, after twenty years of uninterrupted growth, the destination has experienced stagnation (see Figure 3 and 4).During the seventies and eighties there was a multiple rise in the prices of fuel, due to the global economic crisis, and it has affected the demand for charter flights (Iribas \& Gaviria, 1974)

The intermediary companies and tour operators finally reached the local network by increasing the prices. Almost identical things happened in Macedonia, and in addition to this, there was a growth of labor costs in the area of tourism. In this context, the consolidation phase (1981-1985) and the re-emphasis on tourism are starting, with significant role for state travel agencies and local tourism organizations. At this stage, the total number of tourists increased by 30\% compared to the preliminary stage. Shortly after came the phase of stagnation (1986-1988) when investment in hospitality and tourism shrank. Nervertheless, a number of 1,183,160 tourists and 3,978,028 overnight stays was reached. In 1987 the Assembly of Yugoslavia adopted a Strategy for development of tourism in Yugoslavia where a particular place was given to Macedonia. Still, starting from 1988 unfavorable trends in tourism were recorded as a result of economic and political crisis.

The last phase is the phase of decline (1989-1990) characterized by a decrease in the total number of tourists, tourist spending, the quality of the tourist product, social problems, instability, resulting in armed conflict and the beginning of the disintegration of Yugoslavia. Tourism continues to exist even after 1991, i.e from the dissolution of Yugoslavia and the declaration of independence of the Republic of Macedonia. 
This is connected with the beginning of a new cycle of the life of tourism. Again tourism was put in transition, and a process of discovery started, or a new series of cycles according to Butler. The 1991-2001 interval for the Republic of Macedonia is quite unstable and with the destructive effect of a number of destabilizing events (economic crisis, sanctions, blockades, political instability, internal ethnic conflict, etc.), and, of course, a decline in the number of tourists at 333,308, a decline of 849,852 tourists or $255 \%$ less than 1987. In 1993, the statistics registered 73 hotels, 11 motels, 26 workers' resorts, 18 boarding houses, 34 nights, 5 spa resorts, etc.(Dimitrov \& Koteski, 2015; Panov, 1996; Stojmilov \& Tosevska, 2016).

From 2001 onwards, the fifth Talc model started, which included a constructive tourism cycle. Namely, it started with new studies, low-key and rare visits, followed by the inclusion of a new type of tourist demand of educated and experienced people who were interested in finding new forms of tourism that were affected by the uniqueness of the location, therefore giving greater importance to rural areas, cultural, urban and spa tourism (Ca `noves, \& Villarino \& Priestley \& Blanco, 2004; Petrevsak \& Krainer, 2016).

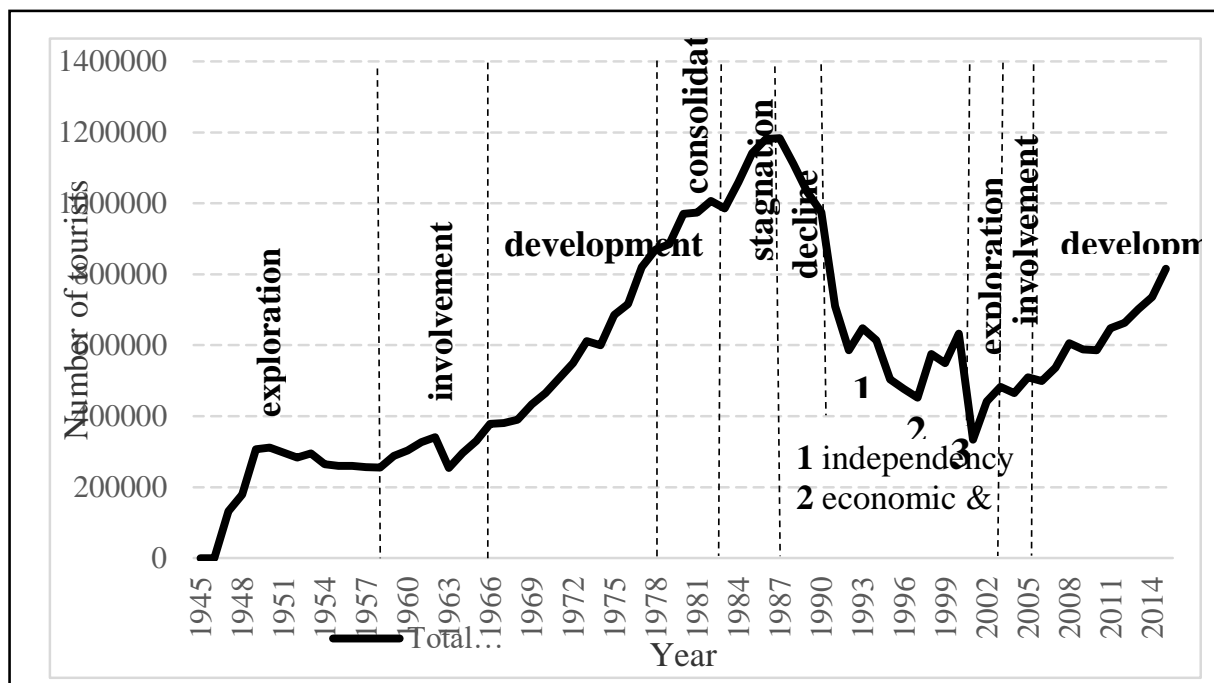

Source: SSO, 1956-1988; SSO, 1991-2016; SSO, 2003-2009; 2006-2015

Figure 4. The movement of tourists in R. Macedonia for the period 1945-2015

The modernization of privatized hotels and the construction of new ones is underway, new modern restaurants and other catering facilities are being modernized and built. Private accommodation in tourist resorts is increasing and becoming competitive. These forms of tourism suddenly saw much greater demand, which increased the total number of tourists, while traditional (lake) sun and sand embraced new strategies and emergent products in order to become rationalized (Clave, 2004).

The progressive development of the destination began in 2005 through a blend of two general life cycles of mass tourism, which were under consolidation and extension of post-Fordist tourism. These processes are related to the democratization of the phenomenon of tourism and the culmination of the national demand for tourism, which has become dominant in relation to the total level of demand. In Macedonian tourism, this is clearly evident through two processes that are common in the general post-Fordist paradigm: on the one hand, the transfer of tourism whose competencies were previously assumed by the country in favor of supranational bodies such as the decentralization of the tourism authorities and the policies of the new democratic government. 
This was also the time when many local councils began to think about promoting tourism with a new understanding of the implications of the sector for infrastructure development and economic growth in general, which again is closely related to the assumptions of talc and Fordist paradigm. In this context, the new autonomous policy of tourism arising from the decentralization process from 2010 notes the growth of fundamental importance for understanding the evolution of tourism management by moving closer to the location itself. This is especially important because of the greater familiarity and knowledge about the reality of the sector by the local government, their greater contact with business representatives (chambers of commerce, business associations, local entities) and their capacity to deal with the specifics of each destination and find out how to become more specialized and give more attention to the tourists. In this process of transformation and improvement, ICT had a significant impact on Macedonian tourist companies, as the basis for a new technological paradigm and change in tourism consumption. The involvement of the public and private sector to improve the destinations with significant growth of accommodation capacities and the growth of certain types of tourism should also be referred to in this context (Petrevska \& Krainer, 2016).

In this sense, the role of the government is evident in the increased demand for domestic tourism (subsidized climate - termal treatments for pensioners, weekend and monastery tourism, etc.), while international tourism returned to the scene thanks to an increase in certain types of tourism (especially the urban concentrated in Skopje), then the promotion of new activities in lake resorts (Ohrid, Dojran, etc.), expansion of airports, subsidizing low-cost charter flights to several European destinations, subsidized tours for foreign tourists, transformation of demand related sociocultural changes, subsidizing the promotion and organization of numerous events aimed at tourism etc.

In the direction of the development of the prudence, the Agency for promotion and support of tourism, and in the larger cities there are tourist info centers. According to, statistic, in R.M in 2010, had 383 accommodation facilities, of which 147 hotels, 3 boarding houses, 8 motels, 14 huts, 6 spa resorts, 2 mountaineering houses, 84 workers' resorts, 31 children's and youth resorts, 1 youth hostel, 4 other accommodation facilities and 83 Uncategorized Smiles (SSO, 2006-2015). Over 160 travel agencies and 10 tourist info boards worked in the tourism industry.

Finally, the article suggests that we are facing the definitive consolidation of post-Fordism in Macedonia, which is characterized by adjusting the product for tourism especially oriented to the value of territorial resources and tourist experiences.

\section{Conclusion}

The article showed how through analyzing the tourism in Macedonia for the period 1945-2015, the talkt model can be visualized in all phases: "research", "inclusion", "development", "consolidation", "stagnation", declining", "Re-detection" and "rejuvenation". Generally, with few exceptions, the period of R. Macedonia within the SFR Yugoslavia for tourism is a period of adaptation in the field of regulation and development of high value and tourist visit, production and consumption of mass tourism.

However, tourism development, was interrupted by the break-up of Yugoslavia. It took ten years for the new, independent Macedonia to deal with severe economic and political crisis also affecting tourism consumption and to start moving forward again. From the perspective of talc, the article shows how each of the main paradigms which analyze the history of tourism can be understood through a life cycle (earlier applied especially in the case of mass tourism). However, the talc does not offer a complete guide on how the transition from one phase of the life cycle actually works.

Finally, in this article we see how production and consumption of tourism systems faced major structural transformations and produced crises, which were overcome by adaptations to the regulation of tourism, with new institutions, laws, competences, new forms and content in tourist destinations. 


\section{References}

Agarwal, S. (2002). Restructuring seaside tourism. The resort lifecycle. Annals of Tourism Research, 29(1), pp.25-55.

Avraham, E., \& Ketter, E. (2015). Tourism marketing for developing countries: Media strategies for battling stereotypes. Houndmills, Basingstoke, UK: Palgrave Macmillan.

Baseski, I. (1976). Review of thirty Tourism Development, Proceedings of the National Symposium - tourism and environmental protection - Geographical Society of SR Macedonia, Skopje, pp. 123-133 (in Macedonian)

Butler, R. W. (1980). The concept of tourism area cycle of evolution: Implications for management of resources. Canadian Geographer, 24(1), 5-12.

Butler, R. W. (2006). The origins of the tourism are life cycle. In R. W. Butler (Ed.), The tourism area life cycle. Vol. 1. Applications and modifications (pp. 13-26). Clevedon: Channel View Publications.

Butler, R. W. (2009). Tourism in the future: Cycles, waves or wheels?. Futures, 41(6), 346-352.

Butler, R., \& Wall, G. (1985). Introduction: Themes in research on the evolution of tourism. Annals of Tourism Research, 12(3), 287-296 (History of tourism thematic issue).

Buzard, J. (1993). The beaten track: European tourism, literature, and the ways to culture, 1800-1918. Oxford: Oxford Clarendon Press.

Ca `noves, G., Villarino, M., Priestley, G., \& Blanco, A. (2004). Rural tourism in Spain: An analysis of recent evolution. Geoforum, 6, 755-769.

Clave, S. A. (2004). De los procesos de diversificación y cualificación a los productos tur'isticos emergentes. Cambios y oportunidades en la dina'mica reciente del turismo litoral. Papeles de economía española, 102, 316-333.

Dower, M. (1965). Fourth wave: The challenge of leisure. London: Civic Trust.

Dimitrov V. N. \& Koteski, C. (2015). Tourist geography, Stip (in Macedonian).

Inglis, F. (2000). The delicious history of the holiday. London: Routledge.

Iribas, J. M., \& Gaviria, M. (1974). Españ a go-go: Turismo charter y neocolonialismo del espacio. Madrid: Turner.

Garay, L., \& Ca noves, G. (2010). Life cycles, stages and tourism history, The Catalonia (Spain) Experience. Annals of Tourism Research, 38 (2), 651-671

Huybers, T. (2007). Tourism and developing countries. Cehltenham, UK: Edward Elgar Publishing.

Karanfilovski, D. (1967). Outgoing tourism development in the Socialist Republic of Macedonia and its prospects, Geographical considerations, Book 4, Skopje, pp. 78-90 (in Macedonian)

Lagiewski, R. M. (2009). The application of the TALC model: A literature survey. In R. W. Butler (Ed.), The tourism area life cycle, Vol. 1: Applications and modifications (pp. 27-50). Clevedon: Channel View.

Panov, N. (1996). Tourism development in the country, I Proceedings Congress geographers of Macedonia held in Ohrid 26-28.11.1995, Skopje, pp. 311-321 (in Macedonian)

Petrevska, B. \& Krainer, N. C. (2016). Investigating tourism development in Macedonia, 2nd International scientific conference Geobalcanica 2015, 10-12 june 2015, Skopje, Republic of Macedonia, pp 309-316

Pike, S. (2005). Tourism destination branding complexity. Journal of Product \& Brand Management, 14(4), 258-259.

Pemble, J. (1987). The mediterranean passion: Victorians and Edwardians in the South. Oxford: Oxford University Press.

State Statistical Ofice of the Republic of Macedonia (SSO). Statistical yearbook for SFRJ, PRM, SRM, 1956, 1961, 1962, 1966, 1971, 1976, 1981, 1986, 1988, Skopje (in Macedonian)

SSO. Statistical yearbook for Republic of Macedonia, 1991, 1992, 1998, 2001, 2006, 2011, 2016, Skopje (in Macedonian)

SSO. Tourism 2003-2007, 2004-2008, 2005-2009 (in Macedonian)

SSO. Tourism in Republic of Macedonia, Statistical review, 2006-2010, 2007-2011, 2008-2012, 2009-2013, 2010-2014, 2011-2015, Skopje (in Macedonian)

Stojmilov, A. \& Tosevska A B. (2016). Socioeconimic Geography of the Republic of Macedonia, Skopje, pp. 374 (in Macedonian) 